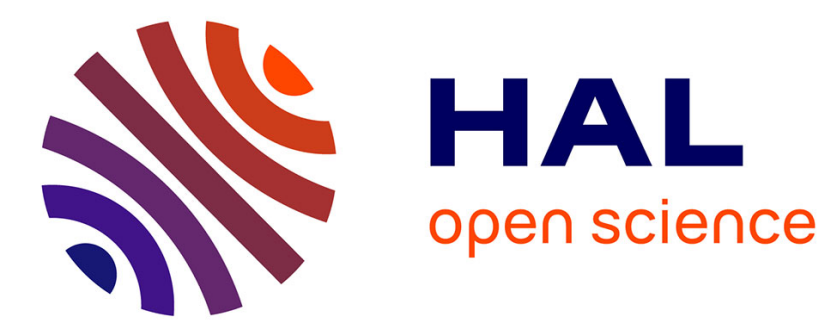

\title{
The Role of Partnership Dynamics in Determining the Acceptability of Condoms and Microbicides
}

Catherine Montgomery, Shelley Lees, Jonathan James Stadler, Neetha Shagan

Morar, Agnes Ssali, Bisalomo Mwanza, Mdu Ntambo, Jessica Phillip, Charlotte Watts, Robert Pool

\section{To cite this version:}

Catherine Montgomery, Shelley Lees, Jonathan James Stadler, Neetha Shagan Morar, Agnes Ssali, et al.. The Role of Partnership Dynamics in Determining the Acceptability of Condoms and Microbicides. AIDS Care, 2008, 20 (06), pp.733-740. 10.1080/09540120701693974 . hal-00513434

\section{HAL Id: hal-00513434 https://hal.science/hal-00513434}

Submitted on 1 Sep 2010

HAL is a multi-disciplinary open access archive for the deposit and dissemination of scientific research documents, whether they are published or not. The documents may come from teaching and research institutions in France or abroad, or from public or private research centers.
L'archive ouverte pluridisciplinaire HAL, est destinée au dépôt et à la diffusion de documents scientifiques de niveau recherche, publiés ou non, émanant des établissements d'enseignement et de recherche français ou étrangers, des laboratoires publics ou privés. 

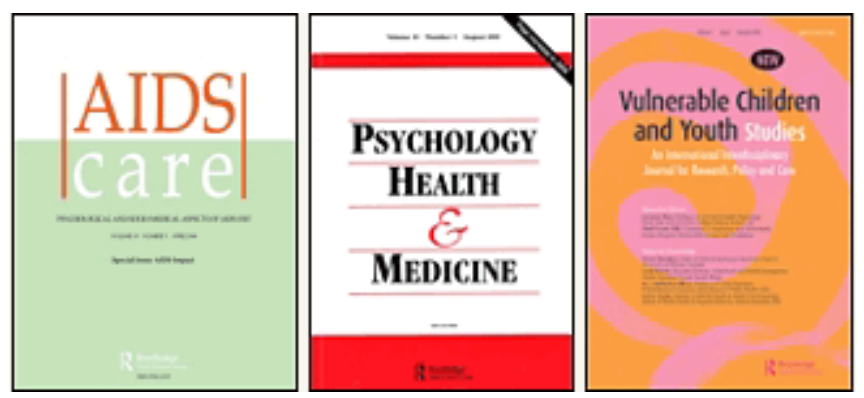

\section{The Role of Partnership Dynamics in Determining the Acceptability of Condoms and Microbicides}

\begin{tabular}{|r|l|}
\hline Journal: & $\begin{array}{l}\text { AIDS Care-Psychology, Health \& Medicine - Vulnerable Children } \\
\text { and Youth Studies }\end{array}$ \\
\hline Manuscript ID: & AC-2007-03-0120.R1 \\
\hline Journal Selection: & AIDS Care \\
\hline Keywords: & $\begin{array}{l}\text { Sub-Saharan Africa, Microbicides, Condoms, HIV Prevention, } \\
\text { Gender }\end{array}$ \\
\hline \multicolumn{2}{|l}{} \\
\hline
\end{tabular}

\section{S) ScholaroNE \\ Manuscript Central}




\section{The Role of Partnership Dynamics in Determining the Acceptability of Condoms and Microbicides}

$\underline{\text { Abstract }}$

Microbicides are a class of substances under development that could reduce the sexual transmission of HIV and other sexually transmitted diseases, when applied locally to genital mucosal surfaces. Microbicide acceptability research has largely focused on product characteristics, rather than processes of negotiation within relationships about use. Gender relations, decision-making power and communication within sexual relationships are recognised as important determinants of condom and contraceptive use, and are likely to determine microbicide use also. As part of social science research linked to the Microbicides Development Programme (MDP), we combine relationship-based theories with anthropological work conducted with women and men using a placebo gel. We explore communication and decision-making in gel and condom use, including constructions of risk and trust.

During the MDP301 Phase III pilot study, in-depth interviews were conducted at sites in South Africa, Tanzania, Uganda and Zambia. Following 4 weeks of placebo gel use, women and their partners were asked about gel use and acceptability, partner involvement, sexual practices, and condom use. Data from 45 couples at 5 sites were analysed using a grounded theory approach in NVivo.

Participation in the study did not require women to inform their partners, yet our data shows women seeking permission from their partners, negotiating disclosure, 
exchanging information, and persuading or motivating for gel use. Although gel was supposedly 'woman-controlled', men exercised considerable influence in determining whether and how it was used. Despite this, negotiations around use were largely successful, since the gel increased sexual pleasure and provided opportunities for intimate communication and the building of trust.

Decisions about condom and microbicide use are made in a dyadic context, and involve a complex negotiation of risk and trust. Whilst preferences relating to product characteristics are largely individual, use itself is dependent on partnership dynamics and the broader social context in which sexual risk management occurs.

Keywords: Sub-Saharan Africa; Microbicides; Condoms; HIV Prevention; Gender 


\section{Introduction}

Microbicides are a class of substances under development that could reduce the sexual transmission of HIV and other sexually transmitted diseases, when applied locally to genital mucosal surfaces. At present, eight compounds are in phase I or II clinical trials and two are in phase III (Alliance for Microbicide Development, 2007). Various mechanisms of action are being investigated, as well as different product formulations, including gels, films, creams and suppositories.

Vaginal microbicides have been heralded as a potential breakthrough in HIV prevention because they are 'women controlled'. Alongside clinical studies of safety and efficacy, acceptability research has been conducted to assess whether new products would be used. Much of this research has focused on hypothetical products, and the desirability of different characteristics (Mantell, Myer, Carballo-Dieguez, Stein, Ramjee, Morar et al., 2005). However, it is also crucial to understand how the use of such products is negotiated within relationships.

Family planning provides a useful precedent, having demonstrated the importance of incorporating both partners in research and interventions. Uptake and sustained use of contraception can be improved when men are involved as partners (Becker, 1996;

Drennan, 1998), due largely to the fact that in many countries, men's influence is pivotal in sexual and reproductive decision-making. The same gendered power relations that 
impact on contraceptive use and in particular, condom use, are likely to impact on the use of a microbicide.

However, disease control research continues to measure sexual behaviour at the individual level through the use of KABP surveys, or through models which see behaviour as individual, voluntary, and rational (Bajos, 1997; Bajos \& Marquet, 2000; Bloor, Barnard, Finlay, \& McKegany, 1993; Rhodes \& Cusick, 2000; Van Campenhoudt, Cohen, Guizzardi, \& Hausser, 1997). A substantial body of research now exists which considers how gender roles, relationship power, communication and decision-making dynamics work within the broader socio-cultural context of sexual relations to impact on women's and men's HIV risk behaviour (Amaro \& Raj, 2000; Harvey \& Bird, 2004),

Most of this research has focused on male condom use. Common findings are the positive association between women's power in a relationship and condom use (Harvey, Bird, DeRosa, Montgomery, \& Rohrbach, 2003; Pulerwitz, Amaro, De Jong, Gortmaker, \& Rudd, 2002), negotiating ability and condom use (Wingood \& DiClemente, 2000) and communication and condom use (Coleman \& Ingham, 1999; Halpern-Felsher, Kropp, Boyer, Tschann, \& Ellen, 2004; Lear, 1995). The literature on factors improving the likelihood of condom use suggests that partner communication is of considerable relevance (Crosby, DiClemente, Wingood, Cobb, Harrington, Davies et al., 2002; Detzer, Wendt, Solomon, \& Dorsch, 1995; Shoop \& Davidson, 1994). Microbicides research and reporting is only now starting to incorporate these discussions (AIDS Alert, 2004; Koo, Woodsong, Dalberth, Viswanathan, \& Simons-Rudolph, 2005; Severy, Tolley, 
Woodsong, \& Guest, 2005). Since any new product is likely to be less effective than the male condom (Foss, Vickerman, Watts, \& Heise, 2002; Smith, Bodine, Wilson, \& Blower, 2005), and hierarchical messages promoting concurrent use are already being formed, social research on the combined dynamics of condom and microbicide use are all the more urgent.

Identifying the determinants and dynamics of microbicide use, particularly in relation to condom use, is essential for the development of effective HIV prevention programmes. In this paper, we use data from both male and female partners to investigate processes of communication and decision-making. We start from the premise that men and women are together intimately involved in negotiations of risk and trust that shape their use of HIV prevention methods. This relationship-oriented approach is particularly appropriate in the light of research demonstrating that even with 'women-controlled' technologies, such as the female condom or microbicides, the male partner's agreement is, or would be, required before use (Beksinska, Rees, McIntyre, \& Wilkinson, 2001; Coggins, Blanchard, \& Friedland, 2001; Pool, Hart, Green, Harrison, Nyanzi, \& Whitworth, 2000; Ramjee, Gouws, Andrews, Myer, \& Weber, 2001; Rees, 1998). We consider the implications for future microbicide introduction.

\section{Methods}


In preparation for a large Phase III clinical trial to assess the safety and efficacy of the candidate microbicide PRO 2000, a pilot study was conducted amongst 320 women at six sites in South Africa, Tanzania, Uganda and Zambia. In South Africa, women were recruited from communities with access to primary health care facilities; in Zambia, through voluntary counselling and testing; in Tanzania, via community outreach to women working in recreational facilities or as food/alcohol vendors in Mwanza; and in Uganda, HIV sero-discordant couples were recruited in Masaka district following census and sero-survey. At each site, a community mobilisation team led recruitment strategies, variously involving public meetings, newsletters, posters, community roadshows, sponsored sports and social events, peer-led education, door-to-door campaigns, and presentations in clinic waiting rooms.

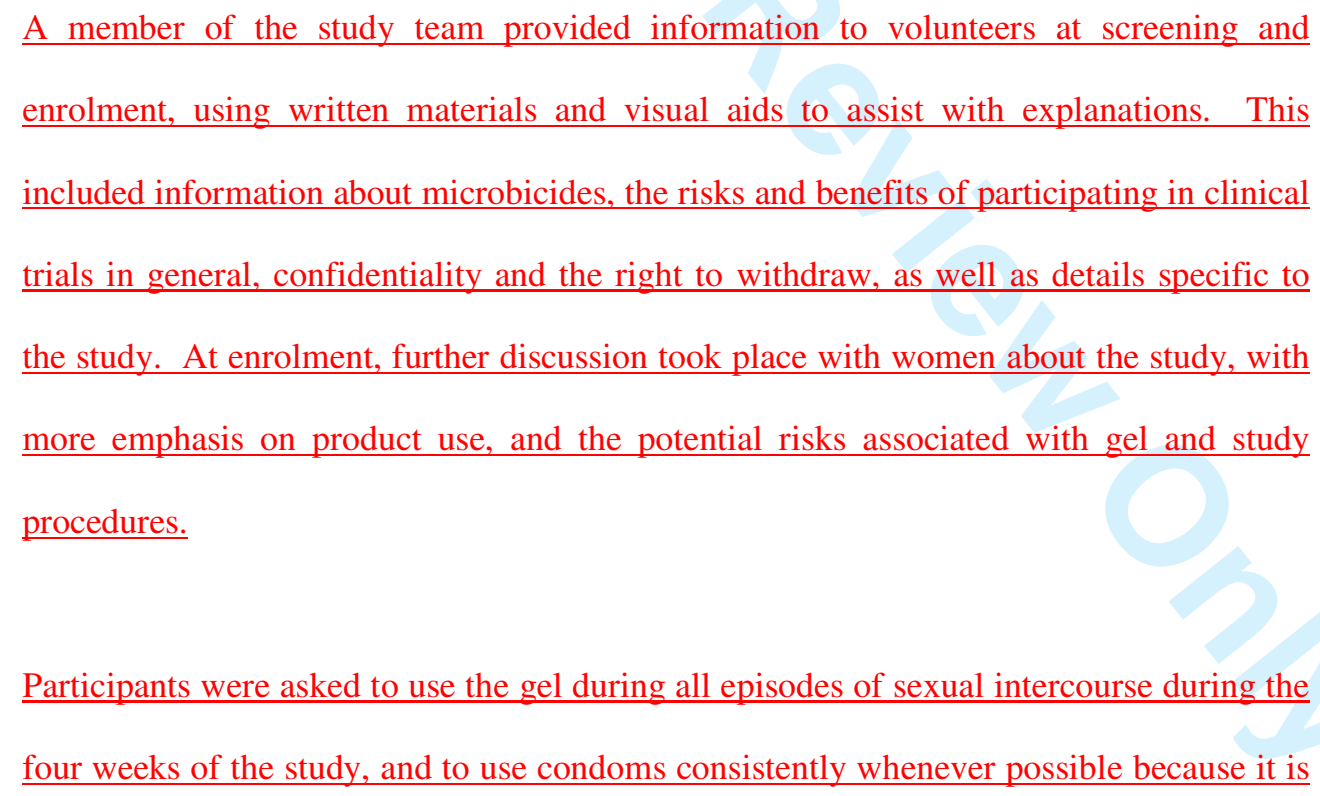


not believed that the placebo gel prevents HIV transmission. At the end of the four weeks, information on sexual behaviour was collected via case record forms. As part of the integrated social science component of the study, in-depth interviews were carried out with all female participants to explore attitudes towards gel and condoms, the extent of partner involvement, and norms surrounding sexual practices. Data was triangulated with information collected in coital diaries, as well as case record forms.

We sought to recruit $10 \%$ of male partners, and asked all women if they were willing for their partner to be contacted. The total number of men interviewed across sites was 45 (15\%). Some women did not wish their partners to be contacted because they had not disclosed their participation in the study to them. A range of contextual factors also $\underline{\text { affected levels of male recruitment for in-depth interviews, most significantly work hours }}$ and employment patterns, which sometimes overrode willingness to participate in the research. A standardised interview guide, translated into local languages, was used at all sites. The topics asked about in the male interviews mirrored those of the female interviews, to allow close comparison of information provided by each partner as part of a couple to be analysed.

Interviews were conducted, transcribed and translated by local social science researchers trained in in-depth interview techniques. Data from forty-five couples at five sites ${ }^{1}$ were entered into NVivo 2.0 (qualitative analysis software) and analysed using a grounded theory approach. Text was coded using inductively generated codes to identify important

\footnotetext{
${ }^{1}$ Data from the sixth site was not available at the time of analysis and is therefore omitted from further discussion in this paper.
}

Deleted: The women were asked to insert a placebo gel into the vagina within 1 hour of each vaginal sex act over a four week period. 
themes, with coded sections then compared within and across cases to generate higher order generalizations (Fielding \& Lee, 1998; Miles \& Huberman, 1994; Strauss \& Corbin, 1998).

Ethics approval was obtained in the UK from the St Mary's Hospital Local Research Ethics Committee and at each site from the national regulatory authority and research ethics committee. Written informed consent was obtained from each participant at screening and enrolment, and verbal consent was recorded prior to each in-depth interview.

\section{Findings}

\section{Disclosure versus Covert Use}

Respondents were asked about the nature and extent of partner involvement, including communication about gel use. Involving partners through disclosure was motivated by several considerations. Firstly, many women said they told their partner about the gel in order to get his permission to use it. The majority of men also said women would have to get their permission before using it, or participating in the research:

"Then I said, let me first go to ask my husband, maybe he can refuse" (Tanzania, $\underline{\mathrm{F})}$ 
"I just gave her permission, I told her that you just go to take them, otherwise had

I refused, I would have told her that you just do away completely with those

things...She wouldn't have managed" (Tanzania, M)

Secondly, both women and men suggested that secrecy or deception in long term relationships was socially unacceptable and deemed immoral or improper. A third and more strongly articulated reason for disclosure was fear of partner violence in the event that covert use be discovered:

"These days when you bring something in the home, you should show your friend so that whatever happens tomorrow he knows. Not keeping it as a secret. What if you are caught? He will beat you, so you should tell your friend that, my husband, this is what I am doing." (Zambia, F)

Very few women felt that it would be possible to use the gel without their partner's knowledge due to the 'wetness' and the change it produced in the way the vagina feels. Male partners agreed that the gel was easily detectable. As such, there was agreement among and across couples at all sites that covert use would be impractical:

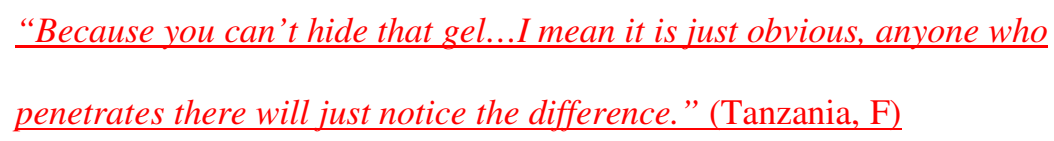


"Even if she will use it secretly, when she goes to have sex with a man, that man

will notice the difference, it will be just a big difference." (Tanzania, $\mathrm{M}$ )

"I: What about if the partner doesn't want to use gel, do you think she will

manage to use it secretly?

R: No, I don't think so." (South Africa, M)

\section{The Disclosure Process}

Disclosure for female participants was a process that in most cases started with the woman's decision to join the study and ended with her partner's agreement to use the gel. Permission-seeking was characteristically followed by resistance from the male partner involving angry disputes. The woman frequently then explained more about the study. In order to persuade her partner to agree, the extensive giving of information also entailed "selling" participation by highlighting the benefits of using the gel. Finally, the male partner would agree. We can condense this process into the following:

\section{PERMISSION-SEEKING - RESISTANCE - PERSUASION - AGREEMENT}

In the interviews, men were frank about the way in which they used their power as 'permission-granters' to obtain more information from their partners. For example, one 
male partner in Tanzania reported that, "I argued just in order to understand it...I really

knew that I will agree with her, but then I can't just agree like that but I must try to probe

her first". Men's initial resistance was both a way to control decisions and a means to

gain more knowledge. Both of these ends can be seen as a means of maintaining power

in the relationship. However, women also alluded to their own power and agency, in

terms of persuasion. Although they required their partner's permission to take part

successfully, their privileged access to knowledge about the gel and the research gave

them some degree of power. Men were particularly keen to be party to this knowledge,

and as such, women had a powerful bargaining tool.

\section{Sexual Pleasure and Continuing Communication}

Women continued to use their powers of persuasion throughout the study to motivate for gel use, whilst men remained dominant in terms of decision-making. Even after they had given their permission, there was some resistance to following study procedures. In Tanzania, in particular, men liked the gel less, due to the increased lubrication, and some had to be persuaded to continue using it. The following is a good example of how women in Mwanza, Tanzania, 'motivated' their partners, in this instance by playing on the partner's responsibility as his wife's guardian:

"On the first day he complained, on the second and third day I told him that let us just persevere and finish this because we were given this as a trial...And it was 
you who allowed me to go there and I have been given those things, what am I going to tell them if we don't use them...So we continued using them until we finished them to the last gel." (Tanzania, F, emphasis added)

In situations where the gel increased men's sexual enjoyment, however, men were frequently the initiators, asking their partner if she had inserted the gel, reminding her to do so, demanding that she use it, or even inserting it for her:

"I used to ask my wife...because she is the one who has it [gel], I would ask her that, "are they there?", "yes they are there, they are not yet finished", I would say "get one, we use", she inserts." (Zambia, M)

Some discussion about the gel also occurred after use e.g. whether or not it was good and whether it produced problems. All couples said either that they openly discussed the gel after use, or that there were no problems in using it, because if there had been, their partner would have told them.

\section{Condoms and Intimacy}

Whilst women could control discussion of the gel, and therefore its use, this was not generally the case for condoms. Although some couples were happy to use condoms and discuss the risk of HIV, many were not. In nearly all cases, men prohibited the 
discussion and use of condoms. This point is interesting, since the purpose of condoms is the same as gel: disease prevention. It is important to ask, therefore, what it was about the gel that made its discussion and use acceptable where the discussion and use of condoms was unacceptable.

The reasons for not wanting to discuss condoms reflect the oft-documented reasons in the literature for not wanting to use condoms: they are strongly associated with disease-risk occasioned through promiscuity or infidelity. As such, even discussing them is a threat to the trust and intimacy of long-term relationships:

“I: And why didn't you use condoms, for example during that period of the pilot study?

R: Now, I mean my husband doesn't even want to hear about those condoms. If you tell him, he tells you "why should we use condoms, am I your boyfriend?"

I: What does he mean when he says so?

R: He tells you that you want us to use condoms, you use condoms if you don't trust someone. Does it mean that you don't trust me?" (Tanzania, F)

This extract highlights that not only do some men not want to use condoms, they do not "even want to hear" about them. Whilst it has often been said that women are unable to negotiate condom use, the emphasis has usually been on the negotiating itself. Our interviews show that women can be good at negotiating and have the necessary skills, but only if there is a space to broach the subject in the first place. In some cases, the very act 
of participating in the study gave women added status, which in turn gave them leverage to discuss using gel. More importantly, though, because the gel was new, it did not carry the same associations as condoms. On the contrary, because of its novelty, it opened up a space for discussion about sex and sexual enjoyment. Unlike condoms, gel provided skin-on-skin contact, which has been strongly linked to intimacy. The added lubrication of the gel meant that both partners tended to enjoy sex more, and as a result, both physical and verbal communication was fostered.

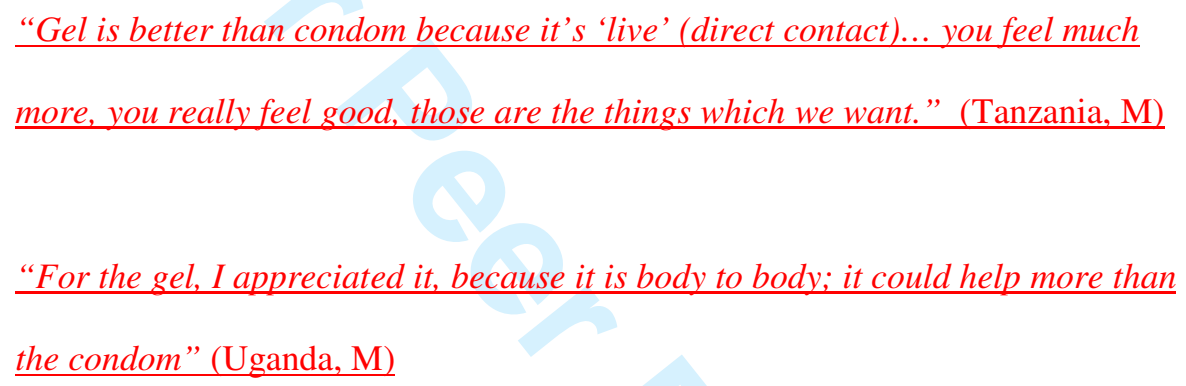

\section{Communication in the Context of Trust and Risk}

A number of men said they would use condoms with 'other women' but not with their wives or main partners, and female participants acknowledged that this was likely to be the case. Interestingly, though, respondents of both sexes said that gel would be suitable for long-term relationships, but not for casual sex. This was reflected in women's choice to tell their main partner about the gel, but not casual contacts: 
“...if he is just a passer-by...I think there is no need of involving him” (Tanzania, F)

"I: Did you inform your two partners that you were using gel?

R: I informed the permanent one but the other one I didn't" (Uganda, F)

Trust was a major consideration for women when deciding on whether or not to tell a partner about the gel. However, it was not a question of telling the partner they trusted, but rather a question of telling the partner they needed or wanted to be trusted by:

"I had to tell him so that he could trust me." (Tanzania, F)

Most women doubted the sexual fidelity or disease status of their partner; their most common reason for participating in the study was wanting to know their HIV status, with nearly all feeling acutely at risk of infection because "men are no longer honest". Male partners concurred, but showed less sense of personal vulnerability, frequently externalising the threat of infection to others. The exception were men who recounted losing a close family member to AIDS, and men in Johannesburg, whose sense of personal risk was very high.

The communication-trust dynamic was pivotal in the acceptance of the gel versus the non-acceptance of condoms. Trust arose explicitly as a topic for women when discussing 
the gel, but as a topic for men only when discussing condoms. Gel disclosure was a means of building trust, whereas suggesting condoms implied a lack of trust. For men, in particular, the association between condoms and lack of trust was all-pervasive: some men said they didn't use condoms because they trust their partner; others because they thought it would make their partner not trust them; and others still because they did not trust the condoms themselves. The gel did not provoke the same response. Men who refused to use condoms, saying they implied a lack of trust, had no problem using the gel, despite its place in the context of an HIV prevention trial. Whilst all participants were counselled that the gel was a placebo which would not protect them against HIV, they were also told that it was a precursor to a similar gel, which it was hoped would protect women from HIV infection by a sexual partner. Thus, the concept of the gel was located within a prevention discourse.

\section{Gel as a Threat to Trust}

Although initiating and discussing gel use did not provoke accusations of mistrust in the way that condoms did, a number of male partners said that the added lubrication made it feel as though their partners had been sleeping with other men:

"R: The gel doesn't have any thing bad about it except that it makes you feel like your partner has already had sex with someone else.

I: ... What other thing didn't you like about the gel?

$\underline{R}$ : Nothing else except that she feels like a gutter 


\section{I: Gutter? \\ R: Yes, elastic like she has already had sex" (Uganda, M)}

In Tanzania, in particular, this was a serious issue due to the preference among study participants and their partners for a tight vagina, associated with virginity or fidelity. Women said that if they didn't tell their partner, he would not trust that she had been faithful. Whilst men emphasised that the added lubrication was acceptable once women had explained about the gel, their comments suggest the type of reputation that could potentially come to stigmatise microbicides if they, like condoms, come to be associated with promiscuity.

\section{Discussion}

The data collected during the MDP pilot study is valuable for understanding acceptability since it comes from actual experiences of gel use, rather than hypothetical situations. Furthermore, by interviewing both partners, it was possible to move beyond the individual and explore gel use within relationships. An obvious disadvantage of the data is that couples were self-selecting, with unsupportive men or those who were not aware of the gel/study not included. Male partners who agreed to be interviewed are likely to have been more supportive, communicative and interested in the research project. They would also only be present from partnerships where the woman had the power to ask her partner if he agreed to be interviewed. 
Whilst all women in the couples presented here told their main sexual partner about their involvement in the study, not all participants in the pilot study did. As such, our findings are unlikely to apply to women who choose not to disclose, whose partners are not longterm, or who live in violent relationships. Although our data show the positive outcome of successful negotiations, this should not mask the fact that some women will have tried to negotiate and failed. In spite of these limitations, the study provides valuable insights into the context in which an effective microbicide will succeed or fail.

HIV has been a non-negotiable risk for many women in sub-Saharan Africa because condoms have been the only way to avoid infection between partners and have largely been controlled by men. Whilst condoms currently offer the best protection against HIV, they are closely associated with physical separation, distance, distrust and disease. It is perhaps unsurprising, therefore, that they are frequently not used. A microbicide gel opens the possibility of negotiation because it is seen as more intimate. Intimacy is the antithesis of the mistrust and uncertainty engendered by risk discourses of sexual safety and disease (Rhodes \& Cusick, 2000).

In addition to being something physically intimate, the gel proved to be a source of trust between partners and therefore fostered relationship strength. Disclosure of gel use and the discussion this engendered produced trust between partners, which, again, could be seen as providing protection from relationship risks, such as separation. In contrast, within the primary partnerships that we were studying, condoms led to a communication 
void, simultaneously being a physical barrier and a barrier to trust and communication.

Rather than being simply a rational response to the risk of disease, discussion of condoms is already an avowal that one or the other partner may be unfaithful; intimacy may be broken and as a result, relationship security threatened.

From the data collected in this study, there is no reason to suggest that because microbicide gel is used by a woman rather than a man, its use will not need to be negotiated. This has also been found in studies in relation to the female condom, another 'woman controlled' device, and another candidate microbicide (Beksinska, Rees, McIntyre et al., 2001; Bentley, Fullem, Tolley, Kelly, Jogelkar, Srirak et al., 2004; Rees, 1998). However, the data suggest that the outcome of this negotiation is more likely to be favourable than for the male condom. Being a product that does not yet carry the negative associations that have attached to condoms, microbicides represent a means of fostering trust between partners, through the very process of disclosure, negotiation and ongoing communication. Indeed, increased sexual pleasure has the potential to cultivate an acceptance of microbicide gels amongst both partners.

In the general context of HIV prevention, Silberschmidt writes that "men will not be inclined to 'involvement' unless they see what are the benefits for themselves" (Silberschmidt, 2004). To a great extent, this appeared to be the case in our study. Male involvement in decision-making extended from initial permission-granting to actively encouraging their partner to use the gel. Whereas the decision to use the gel initiated with the female participants, as the benefits of the gel were experienced, gel use rapidly 
became a domain of joint decision-making. Clearly, then, although the gel was hypothetically designed to protect their partners from HIV, men saw benefits for themselves too.

As our findings highlight, the communication-trust dynamic is pivotal to the use of prevention methods. Our interviews suggest that couples are clearly aware of the need for protection, but want protection that does not bring the pervasive discourse of diseaserisk into the intimacy of their sexual relationship. Because the gel created new grounds for discussion and communication about sexuality, it may have improved the sense of trust between long-term partners, and thus represents the antithesis of the condom. The fact that both partners predominantly thought the gel should be used only in long-term relationships and not between casual contacts further suggests its role in increasing intimacy. It also highlights the extent to which both men as well as women are prepared to use protection where this does not threaten the ideals of relationship trust and security.

These findings have implications for first order introduction strategies of microbicides, including product positioning, promotion and marketing. As other reports have suggested, initial promotion to 'high risk' groups, such as commercial sex workers, could rapidly result in microbicides being associated with disease prevention and/or infidelity, and so prevent their uptake by those who arguably need them most: married women and those in long term relationships (Access Working Group of the Microbicide Initiative, 2000). Couple acceptance will be sensitive to risk and trust discourses at local community, national and international level. If, as our preliminary findings indicate, gel 
is acceptable to individual couples on the basis that it increases sexual pleasure, partner communication and sense of trust, it will be important to foster an environment in which it is also socially and culturally acceptable to use microbicides.

Our data suggest that partnership dynamics play a key role in determining the acceptability of condoms and future microbicides. As candidate vaginal microbicides proceed through development and clinical testing, there is a pressing need for further social research into the dyadic use of gel and condoms. Whilst some women will choose to use the product covertly, this study shows that for those who don't, negotiation is likely to persist around use. Because of this it is important that in referring to microbicides as 'women-controlled' we do not mask the fact that much work remains to be done with both men and women around the gendered power relations which ultimately determine acceptability and use.

\section{Acknowledgements}

The authors are grateful to the participants who took part in the MDP301 pilot study. We also acknowledge the committed work of MDP staff who contributed to the data collected and analysed for this paper, in particular Angel Khathi, Patrick Sosibo, Thokozani Mbokazi, Johannes Dindi, Serah Kalumbilo, Miriam Musonda, Makasa

Deleted: This study shows that negotiation is likely to persist around use, even if some women choose to use the product covertly. 
Chilatu, Irene Mbabazi, Robert Lubega, Winifred Nalukenge, Henry Luwugge, Vinen Khubeka, Siyasanga Nkunwana, Ethel Qwana, Joyce Wayomi, Lemmy Medard, Gilbert Bugeke, Stanislaus Shitindi, Happy Ng'abi and Andrew Vallely. We would like to thank Julie Bakobaki and Lori Heise for commenting on earlier drafts of the manuscript. This study was funded by a grant from the UK Department for International Development (DFID), administered through the Medical Research Council's Clinical Trials Unit. 


\section{References}

Access Working Group of the Microbicide Initiative (2000). Preparing for Microbicide Access and Use: The Rockefeller Foundation.

AIDS Alert (2004). Disclosure is an issue with microbicides testing: Cultural, family, other issues may pose obstacle pp. 105-106).

Alliance for Microbicide Development (2007). Microbicide Candidates in Ongoing Clinical Trials: Summary as of September 2007.

Amaro, H., \& Raj, A. (2000). On the margin: Power and women's HIV risk reduction strategies. Sex Roles, 42(7-8), 723-749.

Bajos, N. (1997). Social factors and the process of risk construction in HIV sexual transmission. Aids Care, 9(2), 227-237.

Bajos, N., \& Marquet, J. (2000). Research on HIV sexual risk: Social relations-based approach in a cross-cultural perspective. Social Science \& Medicine, 50(11), 1533-1546.

Becker, S. (1996). Couples and reproductive health: A review of couple studies. Studies in Family Planning, 27(6), 291-306.

Beksinska, M.E., Rees, V.H., McIntyre, J.A., \& Wilkinson, D. (2001). Acceptability of the female condom in different groups of women in South Africa--a multicentred study to inform the national female condom introductory strategy. S Afr Med J., 91(8), 672-678.

Bentley, M.E., Fullem, A.M., Tolley, E.E., Kelly, C.W., Jogelkar, N., Srirak, N., Mwafulirwa, L., Khumalo-Sakutukwa, G., \& Celentano, D.D. (2004). Acceptability of a microbicide among women and their partners in a 4-country phase I trial. American Journal of Public Health, 94(7), 1159-1164.

Bloor, M.J., Barnard, M.A., Finlay, A., \& McKegany, N.P. (1993). HIV-related risk practices among Glasgow male prostitutes: reframing concepts of risk behaviour. Medical Anthropology Quarterly, 7(2), 152-169.

Coggins, C., Blanchard, K., \& Friedland, B. (2001). Men's Attitudes towards a potential vaginal microbicide in Mexico, Zimbabwe and the USA. Aids, 15, S29-S29.

Coleman, L., \& Ingham, R. (1999). Contrasting strategies used by young people to ensure condom use: some findings from a qualitative research project. Aids Care, 11(4), 473-479.

Crosby, R.A., DiClemente, R.J., Wingood, G.M., Cobb, B.K., Harrington, K., Davies, S.L., Hook, E.W., \& Oh, M.K. (2002). Condom use and correlates of African American adolescent females' infrequent communication with sex partners about preventing sexually transmitted diseases and pregnancy. Health Education \& Behavior, 29(2), 219-231.

Detzer, M.J., Wendt, S.J., Solomon, L.J., \& Dorsch, E. (1995). Barriers to condom use among women attending planned parenthood clinics. Women \& Health, 23, 91$\underline{102 .}$

Drennan, M. (1998). Reproductive Health: New Perspectives on Men's Participation, Populations Reports, Series J, No. 46. Baltimore: Johns Hopkins School of Public Health. 
Fielding, N.G., \& Lee, R.M. (1998). Computer analysis and qualitative research Thousand Oaks, CA and London: Sage

Foss, A., Vickerman, P., Watts, C., \& Heise, L. (2002). Shifts in condom use following microbicide introduction: Should we be concerned? AIDS and Behavior, 17, 1227 $-1237$

Halpern-Felsher, B.L., Kropp, R.Y., Boyer, C.B., Tschann, J.M., \& Ellen, J.M. (2004). Adolescents' self-efficacy to communicate about sex: Its role in condom attitudes, commitment, and use. Adolescence, 39(155), 443-456.

Harvey, S.M., Bird, S.T., DeRosa, C.J., Montgomery, S.B., \& Rohrbach, L.A. (2003). Sexual decision-making and safer sex behaviour among young female injection drug users and female partners of IDUs. The Journal of Sex Research, 40(1), 50$\underline{60 .}$

Harvey, S.M., \& Bird, S.T. (2004). What makes women feel powerful? An exploratory study of relationship power and sexual decision-making with African Americans at risk for HIV/STDs. Women \& Health, 39(3), 1-18.

Koo, H.P., Woodsong, C., Dalberth, B.T., Viswanathan, M., \& Simons-Rudolph, A. (2005). Context of acceptability of topical microbicides: Sexual relationships. Journal of Social Issues, 61(1), 67-93.

Lear, D. (1995). Sexual Communication in the Age of AIDS: The Construction of Risk and Trust Among Young Adults. Social Science \& Medicine, 41(9), 1311-1323.

Mantell, J.E., Myer, L., Carballo-Dieguez, A., Stein, Z., Ramjee, G., Morar, N.S., \& Harrison, P.F. (2005). Microbicide acceptability research: current approaches and future directions. Social Science \& Medicine, 60(2), 319-330.

Miles, M.B., \& Huberman, A.M. (1994). Qualitative Data Analysis: An Extended Sourcebook Thousand Oaks, CA: Sage

Pool, R., Hart, G., Green, G., Harrison, S., Nyanzi, S., \& Whitworth, J. (2000). Men's attitudes to condoms and female controlled means of protection against HIV and STDs in south-western Uganda. Culture Health \& Sexuality, 2(2), 197-211.

Pulerwitz, J., Amaro, H., De Jong, W., Gortmaker, S.L., \& Rudd, R. (2002). Relationship power, condom use and HIV risk among women in the USA. Aids Care, 14(6), 789-800.

Ramjee, G., Gouws, E., Andrews, A., Myer, L., \& Weber, A.E. (2001). The acceptability of a vaginal microbicide among South African men. International Family Planning Perspectives, 27(4), 164-170.

Rees, H. (1998). The search for female-controlled methods of HIV prevention. Agenda, 39(44-49).

Rhodes, T., \& Cusick, L. (2000). Love and intimacy in relationship risk management. Sociology of Health \& Illness, 22, 1-26.

Severy, L.J., Tolley, E., Woodsong, C., \& Guest, G. (2005). A Framework for Examining the Sustained Acceptability of Microbicides. AIDS and Behavior, 9(1), 121-131.

Shoop, D.M., \& Davidson, P.M. (1994). AIDS and adolescents: the relation of parent and partner communication to adolescent condom use. Journal of Adolescence, 17, $\underline{137-148 .}$

Silberschmidt, M. (2004). Men, male sexuality and HIV/AIDS: Reflections from studies in rural and urban East Africa. Transformation, 54, 42-58. 
Smith, R.J., Bodine, E.N., Wilson, D.P., \& Blower, S.M. (2005). Evaluating the potential impact of vaginal microbicides to reduce the risk of acquiring HIV in female sex workers. AIDS 19, 413-421.

Strauss, A., \& Corbin, J. (1998). Basics of qualitative research. Techniques and procedures for developing grounded theory Thousand Oaks, CA and London: Sage

Van Campenhoudt, L., Cohen, M., Guizzardi, G., \& Hausser, D. (1997). Sexual Interactions and HIV Risk. New Conceptual Perspectives in European Research London: Taylor \& Francis

Wingood, G.M., \& DiClemente, R.J. (2000). Application of the Theory of Gender and Power to Examine HIV-Related Exposures, Risk Factors, and Effective Interventions for Women. Health Education \& Behavior, 27(5), 539-565. 